\title{
Can we detect an effect of unemployment on cardiovascular morbidity or mortality?
}

\author{
D.G. Cook
}

Department of Clinical Epidemiology and General Practice, Royal Free Hospital School of Medicine, London NW3 $2 P F, U K$.

\section{Introduction}

Although an extensive literature now exists on the relationship of unemployment to health, few studies have focused on physical, as opposed to psychological, health. This is not surprising since we are presumably looking for small effects of unemployment on physical health, in the presence of strong selection effects of the less healthy into unemployment. Worse still, time lags may exist between exposure and the occurrence of events, while unemployment is not a static condition and confounding social factors abound.

This paper concentrates on the question: can we detect an effect of unemployment on cardiovascular morbidity or mortality? Existing studies may usefully be divided into three groups: macro-economic, general population and factory closure.

Macro-economic studies relate changes in national mortality statistics over time to other socio-economic time trends. Three studies have looked specifically at cardiovascular mortality, in the United States (Brenner, 1971), in Australia (Bunn, 1979, 1980), and in Britain (Brenner \& Mooney, 1982). It is argued that such studies have inherent methodological weaknesses, and that the claims based on them can not be accepted in the absence of other supporting data.

There are only two general population studies, the British Regional Heart Study (Cook et al., 1982) and the OPCS Longitudinal Study (Moser et al., 1984). The Regional Heart Study will be presented in some detail. Details of the OPCS Longitudinal Study appear elsewhere in this issue (Moser et al., 1986); in summary, the study found no statistically significant increase in cardiovascular mortality, over the next 10 years, for men seeking work at the time of the 1971 census by comparison with those employed. A small excess for the wives of unemployed men was found.

Only one factory closure study, the Michigan study of factory closure (Cobb \& Kasl, 1977), has an adequate methodology to warrant its inclusion.

Such a review should be viewed within a wider context (Cook \& Shaper, 1984). In particular, space

Correspondence: D.G. Cook B.Sc., M.Sc. precludes consideration of issues such as: what is meant by unemployment (each study defines the unemployed in different ways, while some use it as a synonym for recession); the non-uniformity of the experience of unemployment; taking account of the effects of re-employment, perhaps at less skilled levels (Bartley, 1986); and the interrelationship of stress and poverty (Jackson \& Warr, 1984).

\section{Macro-economic studies}

The most obvious way in which to monitor the effects of a recession on the health of a country is to compare the changes in unemployment with those in mortality over time.

The studies of Brenner have dominated the literature and have led to a general debate on the limitations of such an approach (Kasl, 1980) and to the specific shortcomings of Brenner's analyses (Gravelle et al., 1981). Brenner's fundamental premise is that the long term upward trend in real per caput incomes during this century is the explanation for the decline in mortality. Brenner goes further, he believes that fluctuations about the general increase in prosperity, which represent recessions followed by periods of rapid economic growth, are stressful to certain groups in the workforce (not just the unemployed) and, by extension, to their families. Rapid economic growth and recessions will therefore be associated with an increase in suicides and in the long term with chronic diseases such as ischaemic heart disease. Thus over a period of several years we can expect economic instability to bring about a deceleration in the decline in mortality.

Such an approach avoids the problems of selection and confounding which bedevil studies of individuals. Unfortunately it suffers from several major limitations: (i) Reliability of the data. Changes in the manner of collecting data often occur over time. This is particularly true of death certification, which can make it difficult to interpret changes in specific ICD 
categories (Clayton et al., 1977). (ii) Choice of explanatory variables. This is limited by what is available. In particular, omitted variable bias will exist, since it is often impossible to obtain suitably aggregated data on important factors affecting disease, such as smoking and diet. (iii) The lag problem in time series analyses arises out of our ignorance of the latent period necessary for an effect of unemployment on mortality to be detectable (Eyer, 1977). (iv) Instability of such time series is to be expected since the meaning of unemployment for individuals and society changes over time. For overall mortality in the UK the effect of unemployment was apparently detrimental between 1922 and 1951, but beneficial between 1952 and 1976 (Gravelle et al., 1981). (v) Who is affected? From aggregated data, it is not possible to make statements about individuals who are unemployed or about specific areas suffering from high concentrations of unemployment.

All these points make it impossible to conclude that association, if found, implies causation. Worse still, lack of association does not imply that unemployment does not have a health impact on some sections of our society.

Kasl (1979), in an excellent review of the methodology and objectives of such studies, considered the claim of Brenner (1971) and others that unemployment was affecting cardiovascular trends in the United States. Kasl pointed out that the decline in cardiovascular mortality since the mid 1960s had coincided with reduced consumption of tobacco, dairy produce and animal fats. There were also reports of serum cholesterol showing a modest fall, while control of hypertension had probably improved. Despite such a suggestive picture he said that epidemiologists were 'taking the stand that the decline cannot be definitively interpreted'.

More recently, Brenner \& Mooney (1982) aimed to explain the recent declines in cardiovascular mortality rates in Britain. Apart from the general criticisms made above, two specific criticisms can be levelled at this paper. Firstly, the models appear to fit remarkably well, with over $90 \%$ of the variability in cardiovascular mortality being explained. Such good fits are rather less meaningful when it is realised that up to 9 explanatory variables have been used to predict only 22 years data. In addition, lags are estimated from the data for several of the explanatory variables, which enhance the fit even in the absence of true association.

Secondly, age adjusted cardiovascular mortality rates are used as indices of mortality in a given year. These age adjusted cardiovascular rates for men exhibit a general decline between 1955 and 1976, with some fluctuations. Unfortunately, age standardization assumes that age specific rates behave in a similar manner over time. This was not the case, though it is impossible to glean from the paper since no raw data is displayed in any form. However, from $1950-52$ to 1970-72 arteriosclerotic/ischaemic heart disease, other myocardial degeneration/insufficiency plus hypertensive disease increased at all ages under 65 , the age groups of greatest interest to unemployment and health researchers (Clayton et al., 1977). Admittedly Brenner \& Mooney use a slightly broader category which includes cerebrovascular disease and rheumatic heart disease; however, we know that for men aged under 65 years circulatory disease mortality was greater in 1973 than in 1951 while for older ages the reverse is true (OPCS, 1978). Since any age standardized rate is dominated by the large number of deaths at older ages it is not surprising that the age-standardized rate used by Brenner \& Mooney decreased over time.

\section{The British Regional Heart Study}

This is a prospective study of cardiovascular disease in 7735 men aged 40-59 years who were randomly selected from the age-sex registers of representative general practices in 24 British towns and invited for interview and examination between January 1978 and June 1980 . The study population of 7735 represents a $78 \%$ response rate.

In a cross-sectional analysis, the frequencies of $\vec{\varphi}$ several factors, including objectively measure $\stackrel{\circ}{\circ}$ physical disease in employed and unemployed meto enrolled in the study were compared (Cook et al. 1982). Men were unemployed if they did not have a current job. The unemployed men in the study were divided into the ill unemployed $(n=258)$ who said their unemployment was due to ill-health and the notill unemployed $(n=158)$ who said that their unemployment was not due to ill-health. Significantly more ill health was found amongst the unemployed compared to the employed, at the time of screening, with regard to three objective measures of health: chronic bronchitis, obstructive lung disease and ischaemic heart disease; the not-ill unemployed exhibited prevalence rates intermediate between those of the employed and the ill unemployed. It is interesting that there were no differences in the prevalence of hypertension between the employment categories. Hypertension is symptomless during much of its history; it therefore differs from bronchitis, obstructive lung disease, and ischaemic heart disease in that it will not be noted by the men and may well not be diagnosed by a doctor.

In a cross-sectional analysis it is difficult to assess how much of these differences are attributable to confounding social factors, nor whether unemployment or ill-health come first; a more dynamic view of the unemployment health relation is needed.

To obtain this dynamic view we are using informa- 
tion from a postal questionnaire to all men at 5 years after entry into the study. The questionnaire asks about employment status before and after entry into the study, and also into changes in health (recall of doctor diagnosis) and in risk factors (smoking, drinking, weight). The illness data are validated by the follow-up procedures linking each man's general practice with the Regional Heart Study. Despite movement between practices, we have maintained contact with $99 \%$ of the men. The questionnaire has achieved a very high response rate $(98 \%)$ and, in conjunction with the measurements made at initial examination, should enable us to examine the extent to which men have been selectively forced out, or kept out, of the work force because of ill-health. It will also be possible to examine changes in smoking and drinking patterns in relation to changes in employment status.

\section{The Michigan study of factory closure}

The field work for this study took place in 1967, and since then it has become the most widely quoted study on redundancy and health, not only due to its priority, but because it is built on a careful methodology and unlike other studies of factory closure has a control group. The health of 100 married men aged 40-59 years in two factories, with an average of 18 years service, was monitored before and after the closure period, extending to 24 months after closure (Cobb \& Kasl, 1977). The health of 74 men from three control factories, 'matched' by factory for job type and location, was monitored over the same period. The numbers were limited not only because the methodology made it impossible to include more factories, but also because a decision was made that a high and continued response over the period of the study was a prime requirement; consequently men were not pressed to participate.

The data were collected by specially trained public health nurses who visited the men in their homes: on each visit they collected blood and urine specimens, took blood pressure, pulse rate, height and weight, and administered a structured interview to collect social, psychological and health data. Members were also asked to keep a health diary.

So far as the results are concerned, this study should be looked on as a pilot. The report points out 'it is not reasonable to generalise from the present experience, limited to two plants . . . [both] . . . involved with one union'. Some of the conclusions were that: (i) 'in the psychological area there were patterns of change and differences from controls which bespoke relationships meaningful to the experience of losing a job'; (ii) physiological changes suggested that in a larger sample an excess of diabetes, peptic ulcer and gout might appear and that there may have been a temporary increase in atherogenesis which might have future implications (sic). Early findings on blood pressure (Kasl \& Cobb, 1970) should not be readily accepted since the final report reveals problems of referral by staff for treatment.

\section{Discussion}

Many authors have documented the role of unemployment in increasing psychological distress (Warr, 1985), but few have looked for, and none have satisfactorily shown an increase in cardiovascular disease.

Claims for recessions having a large impact on cardiovascular mortality rates have come from economists (Brenner, 1971; Brenner \& Mooney, 1982; Bunn, 1979, 1980), whose assertions are based upon macro-economic studies of time series. Their claims should be dismissed in the absence of corroboratory evidence from other sources.

By comparison, studies of individuals have been few. So far the Regional Heart Study is one of only two general population studies to compare adequately the physical health of the employed and unemployed; so far it has presented only cross-sectional results (Cook et al., 1982). Perhaps the most important message to be extracted from the Regional Heart Study analysis is that proxy measures of health such as health care utilization or self-assessment are likely to be woefully inadequate in studies which relate unemployment to physical health. Only the prospective component of the study will enable an assessment of the extent to which poor physical health is a determinant in selecting those made redundant or taking early retirement. Such a step is important if we wish to interpret confidently associations between physical ill-health and unemployment.

The evidence so far does not suggest that the physical health consequences of unemployment are specifically cardiovascular, nor that the effect on cardiovascular morbidity or mortality is large. It may prove easier to detect changes in physiological and biochemical measures. These not only reflect behavioural changes, but are also important in linking psychological to physical ill health. The Michigan study is important because it demonstrated the viability of detecting short term changes in such variables. The difficulty lies in determining the long term implications of such short term changes. Evidence of behavioural changes as a result of unemployment is at present limited (e.g. Warr \& Payne, 1983). Convincing evidence will only come from large scale representative studies of people becoming unemployed.

In the past, redundancy studies, such as the Michigan factory closure study, had somewhat dif- 
ferent aims from studies of the long term unemployed. The present recession has altered the rules and the two approaches now need to be married; the effects of job termination need to be followed into long term unemployment or into re-employment possibly at lower salaries or in less skilled jobs. Such studies require epidemiologists, sociologists and experts on stress to work together.

The current recession is an economic experiment, on which epidemiologists have largely failed to capitalize. The thought of organizing detailed followup studies at short notice, obtaining the cooperation of management, unions and workers when their priorities lie elsewhere is daunting. However, while the

\section{References}

BARTLEY, M. (1986). Redundancy and health in: Redundancy, Layoffs and Plant Closures: the social impact. Lee, R.M. (ed). Croom Helm: London.

BRENNER, M.H. (1971). Economic changes and heart disease mortality. American Journal of Public Health, 61, 606.

BRENNER, M.H. (1979). Mortality and the national economy: a review, and the experience of England and Wales, 1936-1976. Lancet, ii, 568.

BRENNER, M.H. \& MOONEY, A. (1982). Economic change and sex-specific cardiovascular mortality in Britain 1955-1976. Social Science and Medicine, 16, 431.

BUNN, A.R. (1979). Ischaemic heart disease mortality and the business cycle in Australia. American Journal of Public Health, 69, 772.

BUNN, A.R. (1980). Ischaemic heart disease mortality and the business cycle in Australia, II. American Journal of Public Health, 70, 409.

CLAYTON, D.G., TAYLOR, D. \& SHAPER, A.G. (1977). Trends in heart disease in England and Wales, 1950-73. Health Trends, 9, 1.

COBB, S. \& KASL, S.V. (1977). The consequences of job loss. N.I.O.S.H. Research Report, U.S. Department of Health, Education and Welfare, publication no. 77-224.

COOK, D.G., CUMMINS, R.O., BARTLEY, M.J. \& SHAPER, A.G. (1982). Health of unemployed middle-aged men in Great Britain. Lancet, i, 1290.

COOK, D.G. \& SHAPER, A.G. (1984). Unemployment and health. In Recent Advances in Occupational Health, Harrington, M. (ed). Churchill Livingstone: London.

EYER, J. (1977). Does unemployment cause the death rate to peak in each business cycle? A multifactor model of death rate change. International Journal of Health Services, 7, 625. official unemployment rate in Britain appears to have stabilized, redundancies in the coal, steel and motor industries will continue to occur. Many of these will involve middle aged men. A challenge is there to be taken up by those not too strongly wedded to conventional epidemiology.

\section{Acknowledgements}

The British Regional Heart Study was supported by programme grants from the Medical Research Council from 1975-85. Current funding is from the British Heart Foundation, the Medical Research Council and DHSS.

GRAVELLE, H.S.E., HUTCHINSON, G. \& STERN, J. (1981). Mortality and unemployment; a critique of Brenner's timeseries analysis. Lancet, ii, 675.

JACKSON, P.R. \& WARR, P. (1984). Unemployment and psychological ill-health: the moderating role of duration and age. Psychological Medicine, 14, 605.

KASL, S. (1979). Mortality and the business cycle: some questions about research strategies when utilizing macrosocial and ecological data. American Journal of Public Health, 69, 784.

KASL, S. (1980). Problems in the analysis and interpretatio of ecological data. American Journal of Public Health, 7 413.

KASL, S. \& COBB, S. (1970). Blood pressure changes in men. undergoing job loss: a preliminary report. Psychosomatic Medicine, 32, 19.

MOSER, K.A., FOX, A.J. \& JONES, D.R. (1984). Unemployment and mortality in the OPCS Longitudinal Study. Lancet, ii, 1324.

MOSER, K.A., FOX, A.J., GOLDBLATT, P.O. \& JONES, D.R (1986). Stress and heart disease: evidence of association between unemployment and heart disease from the OPCS longitudinal study. Postgraduate Medical Journal, 62, 797.

OFFICE OF POPULATION CENSUSES AND SURVEYS(1978). Trends in mortality 1951-75. HMSO, London.

WARR, P. (1985). Twelve questions about unemployment and health. In New Approaches to Economic Life, Roberts, B., Finnegan, R., Gallie, D. (eds). Manchester University Press: Manchester.

WARR, P. \& PAYNE, R. (1983). Social class and reported changes in behaviour after job loss. Journal of Applied Social Psychology, 13, 206. 